\title{
El deseo, el cuerpo y el secreto, como formas de subjetivación en María Luisa Bombal
}

\section{Desire, Body and Secrecy as Forms of Subjectification in María Luisa Bombal's Literature}

\author{
Nicolás Román \\ Universidad de Chile, Chile \\ neroman.g@gmail.com
}

Resumen • El problema del deseo en la literatura de Gilles Deleuze posee dos entradas. Por un lado está la articulación biopolítica del deseo, desde donde se desarrollan las técnicas de sujeción, y por otra parte, la construcción del deseo como una realidad autónoma y creativa que tiende hacia su subjetivación. Justamente la narrativa de María Luisa Bombal se encuentra en aquella encrucijada. En sus novelas y cuentos hay un enfrentamiento al dilema de la enunciación del deseo femenino, donde la rigidez de su silenciamiento se vuelve tensa en la incorporación de la agencia subjetiva.

Palabras clave: Bombal, Deleuze, Deseo, Sujeto, Subjetivación

Abstract - The problem of desire in the literature of Gilles Deleuze may be understood from two distinct perspectives. On the one hand, we have the biopolitical interpretation of desire, from which the techniques of subjection have developed, while on the other, there is the construction of desire as an autonomous and creative reality that tends toward its own subjectification. The narrative of María Luisa Bombal is situated precisely at the crossroads between these two perspectives. Her novels and stories confront the dilemma of how to articulate feminine desire, in which the already rigid silence becomes even more unyielding in the presence of a subjective agency.

Keywords: Bombal, Deleuze, Desire, Subject, Subjectification 
La crítica literaria ha tenido dos entradas a María Luisa Bombal. En primera instancia, su literatura ha sido leída como el advenimiento de la vanguardia en un panorama dominado por la literatura criollista; desde este alcance sus textos son valorados como una estrategia de renovación estética, sin connotar su condición de género. La segunda entrada se ha hecho desde el silencio anterior, realizándose una lectura que propone un descentramiento crítico feminista. Dentro de esta disrupción del campo literario (el vanguardismo opuesto al criollismo) se rastrea cómo, desde la fantasía y el mundo onírico, emergen las problemáticas de los sujetos femeninos dentro de la sociedad patriarcal. A este respecto hay diversos trabajos, dentro de ellos el realizado por Patricia Espinosa $(2005)^{1}$, quien en los gestos de erotismo lee una enunciación deseante, crítica y creativa por parte del sujeto femenino. Sin embargo, la lectura del deseo y el erotismo en este enfoque feminista, a pesar de ser recurrente, no es unívoca. Por un lado, está la lectura realizada por Lucía Guerra-Cunningham (1991), quien lee en Bombal una apuesta velada por la escenificación del deseo femenino recurriendo a distintos procesos de enunciación; y por otro lado, la lectura de Kemy Oyarzún (1989) que, a diferencia de la anterior, deja ver que los procesos de enunciación velados y críticos del deseo de esta narrativa no son suficientes para escapar a la trama patriarcal dominante en el lenguaje.

Dentro de este campo, que ha sido dominado por aquella división de las aguas, entre quienes ven en Bombal una exponente positiva de una estrategia de subversión, y quienes no creen suficiente aquella estrategia, se puede instalar una lectura que medie entre ambos puntos de vista, viendo en la incapacidad de María Luisa Bombal una forma de alumbramiento negativo de una subjetividad por no venir necesariamente establecida.

La construcción de aquella hipótesis necesita de materiales de diversa factura para ser fundada. En primer lugar, se debe exponer la postura de Bombal respecto de la pertenencia de su literatura a las reivindicaciones en políticas de género, y en segundo lugar, establecer las técnicas y estatutos en los cuales se basa la edificación de un sujeto. De la misma forma es necesario establecer la preocupación de María Luisa Bombal por el feminismo, debido a que así se pueden leer las filiaciones estéticas y políticas de sus textos. Aunque, si bien se puede interpretar de la manera en que el crítico estime conveniente, un estudio de la relación de María Luisa Bombal con el feminismo hace explícita que la opción feminista, como una elección política y un deseo construido, se genera bajo una matriz subjetiva. Es decir, esta decisión política tiene inscrita en su interior formas de ser mujer, las que no necesariamente han de ser transformadas en un «deber ser», puesto que su devenir es la mediación de una técnica deseante aplicada a la superficie erógena del cuerpo e inscrita como piel discursiva en sus sujetos, por lo que la narrativa en cuestión no se debe ceñir a ese canon por necesidad.

En su artículo: «La última Niebla de María Luisa Bombal: excentricidad, desacato y eroticidad en el devenir identitario femenino", Patricia Espinosa parte desentramando el desacomodo de las figuras femeninas en un espacio privado en crisis. Desde aquella primera ruptura, ella pasa a interpretar los desajustes con los sujetos silenciados por el criollismo (peones, mujeres, etc.), para luego componer el panorama discursivo de la nueva enunciación femenina. 


\section{BOMBAL, SU LUGAR DE ENUNCIACIÓN Y SU RELACIÓN A LA POLÍTICA, A LA ESTÉTICA}

De esta forma, la escritura de María Luisa Bombal no necesariamente debe coincidir con una reivindicación feminista por ser ella un agente creativo dentro de la sociedad; su rol como artista es crítico en la medida que crea nuevas relaciones de sentido a partir de las existentes, inscribiéndolas en una continuidad simbólica a la cual se integra por negación o por asimilación de lo establecido. Siendo las cosas así, las reflexiones en torno a lo estético, lo femenino y lo político, tendrán una especial significación, debido a que su forma de entrar en el campo cultural, en primer lugar no se cifra dentro de una escritura feminista. Así lo afirma la misma María Luisa Bombal en su «Testimonio autobiográfico»: "No me importó para nada el feminismo porque nunca me importó. Sí leía mucho a Virginia Woolf, pero porque sus conceptos los hacía novelas y no daba sermones» (337). Dentro de esta reflexión, está presente lo político y lo estético, enmarcado en el cuadro que correspondería a una escritura feminista. No obstante, la autora de La última niebla hace explícito que el marco de relaciones de sus textos no ha sido el feminismo, más bien, ella se acerca a la reflexión estética de la problemática del género sin caer en la propaganda ni la pedagogía política por medio de la literatura. Por otra parte, la alusión a Virginia Woolf hace referencia a un caso paradigmático de escritura, puesto que su valor es tanto estético como político, ya que en su discurso literario está expuesto el problema de la enunciación femenina, aunque no como sermón.

Dentro de una perspectiva más general, donde se pueda debatir la estética y la política en los textos de María Luisa Bombal, se puede aludir qué considera ella como político, y cómo se relaciona esa esfera con su literatura, por lo cual sería pertinente aludir a sus declaraciones respecto de estos temas publicadas en su «Testimonio autobiográfico»:

Mi compromiso era de tipo moral, no político, y en eso coincido con la actitud de Borges. Además, pensaba que la política era cosa de hombres: ‘QQue se ocupen ellos!〉 A mí me gusta ese árbol, este río [...] ¡Que se frieguen los hombres!... Ellos matan... Yo me dedico a otras cosas (327).

Por medio de las afirmaciones anteriores, lo político no es el campo que restringe las preocupaciones creativas de María Luisa Bombal. Al igual que Jorge Luis Borges, ella ha deslindado su producción de problemáticas tildadas como masculinas y nefastas. En ese mismo orden de ideas, ella ha demostrado intereses minoritarios dirigidos a realidades particulares, a diferencia de lo que son las preocupaciones eminentemente masculinas relacionadas al dominio y la violencia. En ese sentido, el concepto de menor y mayor en Deleuze y Guattari (1997) se ajusta muy bien a lo prescrito por María Luisa Bombal. Primeramente, por definir dos ámbitos frente a los cuales se debate la producción estética: lo político y lo moral, y en segundo lugar, por referir los alcances de ambas esferas. De este modo, la política será el espacio masculino de la dominación y de la acción — «iQue se ocupen ellos!»—, donde por oposición la esfera de lo moral se ocuparía de las preocupaciones minoritarias — «Yo me dedico a otras cosas»-, en las que las realidades singulares cobrarían mayor relevancia que la ejecución de un plan de subordinación. 
Por ende, la disimilación entre lo político y lo moral resuena en el binomio mayor y menor expuesto por Deleuze y Guattari como anteriormente se había enunciado, sin establecer el vínculo entre ambas posturas. En función de lo planteado, el vínculo de aquel cuadro de correspondencias operaría en la lógica deleuzeana, teniendo en cuenta que:

[El] devenir-minoritario es un asunto político y recurre a todo un trabajo de potencia, a una micropolítica activa, justo lo contrario de la macropolítica, e incluso de la Historia, donde más bien se trata de saber cómo se va a conquistar o a obtener una mayoría (Deleuze y Guattari, Mil mesetas, 292).

En resumidas cuentas, la oposición entre lo mayor y lo menor deviene de sus efectos; la dominación y la conquista de la escena histórica versus la proliferación activa de una subjetividad que se escapa al orden de lo binario.

\section{EFECTOS DE SUJETO Y SUBJETIVACIÓN}

En relación a la problemática expuesta es de utilidad el concepto de literatura menor ${ }^{2}$, en la medida que realiza un esfuerzo por descomponer las fuerzas de subordinación que actúan en el campo social. Dentro de este marco es de suma relevancia el traslado del binomio establecido por Bombal entre política y moral al binomio deleuzeano mayormenor. Por otra parte, para seguir derivando aquella resonancia, se puede sumar el par sujeto-subjetividad a la estructura anteriormente descrita, siguiendo el propósito de clarificar los vínculos entre estética y política en la prosa de Bombal, más allá del feminismo.

Pero ¿por qué incidir en aquella disputa establecida con el feminismo? Las críticas feministas que desacreditan el esfuerzo de Bombal por generar una enunciación deseante femenina (Oyarzún, 1989; Garrels, 1991) se basan en su fijación a un imaginario violento, enfermizo, patriarcal y mortuorio, desde donde su enunciación es eclipsada por la subordinación patriarcal, funcionando como reflejo invertido del orden de la ley en la construcción de su deseo. En otras palabras, el deseo de Bombal no sería más que el deseo masculino como si fuese una enunciación femenina. Por otra parte, la crítica que valora estos esfuerzos por demostrar el deseo femenino visto en medio de los pliegues de su escritura (Guerra-Cuningham, 1991; Méndez, 1994; Lucas, 1999 y Carreño, 2002) demuestra cómo, por medio del erotismo y la fantasía, se puede descomponer la trama significante patriarcal. No obstante, el debate más allá de esta tensión se podría circunscribir respecto de cómo se efectúa la subjetivación del deseo en Bombal, la que se opone a una sujeción del deseo, puesto que: «Su escritura adopta el intimismo, lo personal, la subjetividad microscópica y fragmentaria en oposición a una escritura de cuño épico-masculinizante» (Espinosa, 13). Por consiguiente, la discusión puede ser derivada a la construcción del sujeto y la resistencia a esa iluminación por medio de la refracción de aquella técnica, siendo el campo del deseo la opacidad refulgente del pliegue de las fuerzas de sujeción.

\footnotetext{
Una literatura menor es la que opera en un campo dominado por una estructura mayor, por ende, una literatura menor no es una literatura secundaria, sino que es una operación de desmontaje de los efectos de sujeto establecidos por medio del binarismo y la subordinación.
} 
En ese sentido, este trabajo se esfuerza por reunir dos columnas paralelas en la crítica de Bombal categorizadas política y estéticamente. La primera, se funda en el intento de crear un sujeto ligado al feminismo, dispuesto a decir su deseo en sus propios términos, creando una enunciación política relacionada a la visibilidad; empresa que esta narrativa no lograría. Por el contrario, la otra columna se fija en la refracción de aquella posibilidad de luz, con el conocimiento de que el desmontaje del deseo patriarcal requiere de una agencia crítica y prófuga, cuya enunciación no se realizará en términos de luminosidad.

\section{CÓMO DECONSTRUIR UN SUJETO PARA DAR PASO A UNA SUBJETIVIDAD}

María Luisa Bombal tiene muy claro qué es ser un sujeto y las técnicas mediante las cuales éste se establece. Su deslinde del feminismo y su denuesto contra la política demarcan su programa creativo, y junto a su narrativa, estos elementos matizan el trazo de cómo evadir los nudos del poder. Primeramente, se ha establecido cómo se ha desmarcado de la política y del feminismo, lo cual orienta los términos en que se basa su discurso. El descarte de la política y de la pedagogía feminista («sus conceptos los hacía novelas y no daba sermones', refiriéndose a Woolf), demuestra uno de los pilares en los cuales se construye la narrativa de Bombal. Ella no está pensando en la articulación de un movimiento reivindicatorio, que en términos deleuzeanos sería una obra mayoritaria, sino que busca el punto de fuga plegando el efecto de la fuerza que ilumina el sujeto, tal como se afirma en El árbol: «El árbol pegado a la ventana del cuarto de vestir. Le bastaba entrar para que sintiese circular en ella una gran sensación bienhechora. ¡Qué calor hacía siempre en el dormitorio por las mañanas! ¡Y qué luz cruda! Aquí, en cambio, en el cuarto de vestir, hasta la vida descansa» (Bombal, 94).

De este modo, uno de los componentes más importantes de la narrativa de Bombal se hace presente. La luz cruda que invade el dormitorio es la alegoría de la visibilidad social a la cual ella se opone buscando refugio en los espacios minoritarios.

El estatuto que le corresponde a la luz dentro de los sistemas de representación está marcado por la figuración de lo razonable y lo legible, siendo su característica principal ser la metáfora de la diferencia específica del ser humano: la razón. La luz derriba el caos confuso de lo indistinto y establece la identidad por medio de la exclusión de la diferencia. Por lo tanto, es de la luz desde donde se deviene sujeto ${ }^{3}$. La luz captura frente al devenir confuso, la luz establece la diferencia entre horizonte y figura, y distingue la forma de su fondo; por lo que si en el cuarto de vestir la vida descansa frente a la luz cruda, se ha entregado la primera pista para construir la fuga de los presupuestos epistémicos del patriarcado y la sujeción.

Es más, dentro del cuento El árbol hay más referencias a la acción descarnada de la luz: «No puede salir del cuarto de vestir. De su cuarto de vestir invadido por una luz blanca aterradora. Era como si hubieran sacado el techo de cuajo» (Bombal, 104). Aquel pasaje corresponde al momento posterior en que se ha talado el árbol. Éste acogía a la protagonista en las tardes de lluvia, permitiéndole vestirse bajo el halo de su oscuridad. 
Tal vez, la oposición a la forma de articular la subjetividad femenina como una opacidad cauce reticencias en feministas asociadas al paradigma de la igualdad. Sin embargo, la administración de la vida, por medio del bloqueo de la construcción de multiplicidades deseantes, ha dado por resultado la construcción de sujetos ${ }^{4}$. El poder ha mutilado las superficies deseantes y las ha unificado en la construcción de un sujeto doblegado ante el deseo que acompasa la estructura social, por lo cual la tarea de evadir la sujeción puede comenzar en dos direcciones. Una puede ser la construcción de una técnica liberadora, que suponga otro sujeto como si éste fuese la alteridad de la versión hegemónica, o bien, la desterritorialización de las formas de sujeción para dar paso a la subjetivación de los nudos deseantes reprimidos, evadiendo la encorsetada estructura social.

En el caso de las novelas de María Luisa Bombal, los acercamientos críticos se orientan en las direcciones expuestas anteriormente, sería sesgado y autoritario privilegiar una interpretación en pos de la otra. Sin embargo, como antes se había anunciado, la dirección de la crítica apunta en la construcción de dos columnas, estribadas en el antagonismo entre estética y política, las cuales terminan edificando una alocución que busca una nueva forma de subjetividad.

Para ahondar en aquel tema, se puede establecer que la obra de Bombal se relaciona al desmontaje de las técnicas de construcción del sujeto con el fin de entrever la articulación de una subjetivación. Para la comprensión y proyección del valor de esta polémica, la subjetivación en la escena del poder significa lo siguiente:

La subjetivación [es] curvar la línea, replegarla sobre sí misma, conseguir que la fuerza se auto-afecte. De este modo, tenemos un medio para vivir lo que, sin este doblez, no podríamos vivir. Lo que viene a decir Foucault es que sólo podemos evitar la muerte y la locura si hacemos de la existencia un 〈modo〉, un ‘arte〉. Es absurdo pretender que Foucault reintroduce subrepticiamente el sujeto que anteriormente había negado. No hay sujeto, hay producción de subjetividad: precisamente porque no hay sujeto, la subjetividad debe ser producida en cada momento (Deleuze, 182).

Por consecuencia, en las escenas de María Luisa Bombal no existe una proyección de un deseo femenino en tanto construcción de un sujeto, sino que hay una escenificación de la fuerza afectándose a sí misma. Una resistencia al poder y una orientación de la fuerza hacia su punto ciego, tal como se afirma en su «Testimonio autobiográfico»: «Este hecho sobrecogedor, maravilloso, me inspiró para imaginar a una mujer que era tan misteriosa como la naturaleza que los hombres 〈no〉 comprenden ni quieren comprender» (Bombal, 340). Por lo tanto, esa naturaleza incomprendida y no iluminada en Bombal no puede apostar por una reivindicación social, sino que apela a una construcción artística, donde el poder se vuelve sobre los bordes filosos que administran la vida.

4 Con este argumento se hace alusión veladamente a la tarea filosófica realizada por Michel Foucault. El filósofo francés estableció la comprensión discursiva de lo humano por medio de la construcción de un «Saber»; posteriormente analizó la reproducción material de los sujetos por medio de las disciplinas: «El poder». Y por último dedico su trabajo a «La inquietud de Sí» y a cómo escapar de las limitaciones del saber y el poder por medio de la subjetivación. Uno de sus textos que puede eventualmente recoger los tres tópicos es la Historia de la sexualidad. 


\section{LA BIOPOLÍTICA: LA ADMINISTRACIÓN DE LA VIDA Y LA POSTERGACIÓN DE LA MUERTE}

La filiación con el mundo de la muerte y el erotismo en esta narrativa es una de las piezas principales que operan en su imaginario. Aunque éste es criticado y considerado como violento y mimético frente a la violencia social, según Elizabeth Garrels (1991), que basa su crítica en la captura de la enunciación femenina por la mirada fálica. Sin embargo, ahonda en desacreditar el valor literario de la obra de Bombal debido a las reiteradas escenas de violencia:

El que una mujer sólo haya contemplado el adulterio y el suicidio como formas de rebeldía (43) o que haya favorecido la palabra 〈violencia para significar intensidad $(13,14,18)$, se entienden dentro de un orden de las cosas en que la sexualidad está sistemáticamente sometida al poder político y económico en que predominan los discursos de las prácticas de la violencia y la agresión (Garrels, 89).

De este modo, Garrels ve un peso muerto en el pacto mimético a tal punto que la violencia no es una estrategia de enunciación estética sino que es la falta de capacidad creativa. No obstante, esta interpretación cae en la imposibilidad de concebir el desplazamiento metafórico que opera en la base de los textos literarios. Por lo tanto, la lectura de la violencia, orientada hacia una escenificación masoquista de las condiciones sociales, no comprende la puesta en escena que condensa el nudo del poder donde se concentra toda la fuerza de la sujeción en pos de la administración de la vida.

Precisamente, Bombal pone en evidencia la envergadura de la empresa biopolítica, donde la muerte se eclipsa tras el velo de la mantención de los cuerpos productivos. La muerte se ha negado como experiencia. Por lo tanto, explorarla implica emprender una tarea desafiante frente a la moral vitalista del poder: «De acuerdo con la manera en que se pliegan las líneas de fuerza, se constituyen modos de existencia, se inventan posibilidades de vida que implican también la muerte» (Deleuze, 150). En este caso, la voz de Deleuze invoca el pensamiento foucaultiano en su última etapa, cuya premisa es evadir «las líneas del poder en pos de salir de los puntos ciegos que plantean sus articulaciones. En su Voluntad de saber, Michel Foucault descubre cómo el poder funciona en la administración de la vida y la postergación de la muerte, por lo que no queda en duda que el sujeto se erige en esa técnica. Aunque de modo equidistante a Foucault, Bombal está sacando las mismas conclusiones respecto de la vida y la sujeción, como ocurre en La última niebla: «Un destino implacable me ha robado hasta el derecho de buscar la muerte, me ha ido acorralando lentamente» (84). De este modo, la protagonista reacciona frente al suicidio frustrado de Regina, y se da cuenta de que el matrimonio y su vida aburguesada han posado un velo de sujeción capilar que ni siquiera le permite apoderarse del destino de su vitalidad orgánica.

Contrario al argumento de Garrels, el velo mortuorio en Bombal es la forma en que se descubre la naturaleza positiva del poder ${ }^{5}$ en La amortajada: "Había sufrido la muerte de los vivos. Ahora anhelaba la inmersión total, la segunda muerte: la muerte de los muertos» (Bombal, 91). De esta forma, la búsqueda de un espacio fuera de la prisión

En el caso de Foucault el poder no es la entidad negativa de subordinación común y corriente, sino que es un dispositivo que provoca y genera visibilidad; no es solo un poder de captura, es un poder que deja ver. 
biopolítica se localiza en la opacidad del poder donde se prohíbe la posibilidad de autodeterminar la existencia hasta su extinción y más allá. No es que Bombal apele a una proliferación indiscriminada de la violencia, sino que la forma de hacer más tensa la enunciación de los mecanismos biopolíticos, es demostrar la forma descarnada como estos operan aguzando la brecha de su salida, como se postula en La última niebla: «No me siento capaz de huir. De huir ¿cómo, adónde? La muerte me parece una muerte más accesible que la huida [...] Es muy posible desear morir porque se ama demasiado la vida» (Bombal, 47). Como consecuencia, el enfrentamiento al poder tiene un doble resultado, por un lado se desmonta la estrategia crítica que encapsula a María Luisa Bombal fuera del paradigma de lo político, y por otro lado, se demuestra la relevancia de construir un más allá del sujeto plegando la fuerza que lo crea. En otras palabras, la autora vanguardista busca una resolución estética de las contradicciones del poder sobre el sujeto femenino, su enunciación busca la creación de un modo de existencia: una mujer misteriosa o la muerte de los muertos ${ }^{6}$.

\section{¿SUJETO O SUBJETIVACIÓN?}

María Luisa Bombal construye una plataforma que proyecta la muerte como un campo de experiencia sobre la base del espiritualismo de vanguardia. Su esfuerzo no es ajeno a una tradición estética cultivada por artistas y mujeres de principios del siglo xx (Subercaseux, 1999). De esta manera, nuevamente se hace alusión a elementos que construyen la estética de María Luisa Bombal, explicitando que el feminismo no está dentro de las primeras referencias de su repertorio de imágenes. No obstante, sus preocupaciones estéticas resuenan especialmente en la representación micropolítica, desde donde el sujeto deriva a una subjetivación de conexiones deseantes que muchas veces se construyen en base a imágenes del espiritualismo de vanguardia. En tal sentido, y volviendo a lo anunciado anteriormente con respecto al marco que hay entre sujeto y subjetividad, se hará una exposición de las imágenes de María Luisa Bombal que construyen una estética con los referentes del lado oscuro de la razón.

En primer lugar, la relación entre muerte y naturaleza se ahonda como forma de dilución del sujeto. En La amortajada, ad portas de sentir cómo sería la muerte de los muertos, la protagonista se une a la tierra: Ya no deseaba sino quedarse crucificada a la tierra, sufriendo y gozando en su carne el ir y venir de lejanas mareas; sintiendo crecer la hierba, emerger las islas nuevas y abrirse, en otro continente, la flor ignorada que no vive sino en un día de eclipse» (Bombal, 91).

De esta manera, el sujeto nuevamente desoculta sus partes veladas, el eclipse que nace en esta noche de muerte y entierro es una de las formas que tiene la subjetivación de emerger desde la realidad esclerosada. Lo construido en la representación es un modo

\footnotetext{
$6 \quad$ Patricia Espinosa plantea que en la búsqueda de la ubicuidad femenina, Bombal tuerce el espiritualismo de vanguardia, que definido por Subercaseux (1999), se caracteriza por abocarse a las profundidades de la existencia y la inquietud por el irracionalismo como búsqueda de nuevas formas de espiritualidad. En ese mismo sentido, la proximidad de la muerte como oscurantismo cultiva la línea espiritualista, por lo que el descrédito del aura mortuoria hecha por Elizabeth Garrels obvia nuevamente una clave relacionada a la lectura situada de la narrativa de Bombal.
} 
de existencia que evade la línea del sujeto, cuya tangente se cuida de rozar la humedad palpitante de la tierra: «Es precisamente la humedad y la fluidez de una economía libidinal femenina, la que permite en el contexto difuminar las categorías falocéntricas de una sexualidad escindida» (Guerra, 118). En resumidas cuentas, las imágenes se aglomeran para construir una subjetivación del espiritualismo. El desmontaje del sujeto no tiene por qué tener inscrito en su interior otro sujeto que reconstituya en su propia lengua la agencia subjetiva de modo que las zonas blandas de la humedad se vuelvan sólidas en una enunciación monolítica.

De todas maneras, las imágenes de la naturaleza no sólo se nutren del imaginario de la muerte como una esquicia de la crisis del sujeto y su representación. También existen otros elementos que permiten evadir el escollo del sujeto, para poder dar visibilidad al deseo y refractar la luminosidad del poder que oscurece su enunciación. Las imágenes de la naturaleza, sumadas al cuerpo y el agua, todas unidas en una retórica de la erotización, son constantemente descubiertas como las imágenes de resistencia a las alocuciones patriarcales. En ellas, el cuerpo se presenta como una zona erógena respirando los aspavientos de la naturaleza, como en La última niebla: «Tibias corrientes me acarician y me penetran. Como con brazos de seda, las plantas acuáticas me enlazan el torso con sus largas raíces. Me besa la nuca y sube hasta mi frente el aliento fresco del agua» (42). De este modo, la escena del estanque en el relato concibe un despertar del autoerotismo de la protagonista.

Dentro de una perspectiva más general, las manifestaciones del erotismo gracias a elementos de la naturaleza, sea la tierra o el agua, permiten construir una sexualidad desterritorializada, tal vez una actitud deseante que ya ni siquiera sea sexual, debido a que el orden hetero-normativo del sistema sexo-genérico se deconstruye:

Dentro de todo el contexto de la sexualidad transgresiva en la novela, es evidente que el concepto dominante de la penetración fálica como instancia nuclear se contradice para insertar el concepto de una sexualidad múltiple y difusa. El placer solitario en caminatas por el bosque, las ensoñaciones al lado de la chimenea o el estanque, y la escritura misma, son por lo tanto, expresiones de esta sexualidad que sustituye la penetración fálica por la inmersión (Guerra, 118).

De este modo, la inmersión plantea las incógnitas por las cuales se podría eventualmente pasar del plano del sujeto hacia el plano de la subjetividad, debido a que las huellas y delimitaciones del sujeto se han borrado. A su vez, con la elisión de la penetración hay una huida de la sexualidad binaria, donde el falo toma el lugar de significante trascendental, que no sólo es relevante para concretar la disimilación sexo-genérica, sino que también marca el origen de la conciencia al delimitar el campo de lo simbólico.

Si bien Lucía Guerra (1991) establece que el estanque permite desatar la fluidez del deseo, desdibujando los límites que sujetarían el cuerpo, Elizabeth Garrels (1991), desde otra perspectiva, basa su análisis en la fijación escópica del deseo en Bombal, argumentando que: «En ningún momento la protagonista se libera del dominio de la mirada fálica; nunca cuestiona su imperio» (85). Puesto que las imágenes que suceden al estadio del estanque se construyen en base a una alteridad masculina, de hecho, Kemy Oyarzún (1989) establece que después de este episodio, la protagonista pacta el goce que puede sentir en la conexión de su cuerpo con la naturaleza, por el placer que experimenta en la captura de la mirada de su amante imaginado, por lo que: «No [vuelve] al júbilo del estadio del estanque, confundiendo con júbilo el placer represor y sublimado de la negación de sí misma y de su entrega claudicadora al otro» (102). Tanto Garrels como 
Oyarzún desarrollan la constitución de la protagonista de La última niebla, siguiendo el hilo conductor que la relaciona a la esfera masculina, donde según estas perspectivas, el desmontaje de la razón patriarcal encallaría.

Ahora bien, para continuar con el diálogo de las perspectivas críticas, en base al binomio sujeto-subjetivación (que en este instante se inscribe en el campo del deseo), se hará una exposición de las posturas que no ven en la aparición del otro masculino, una alteridad hegemónica que clausura el territorio discursivo de la protagonista. En ese sentido, en $\mathrm{La}$ última niebla, a pesar de constituirse un deseo en diálogo a una alteridad opaca, se pueden establecer tres momentos de la relación deseante con la alteridad. En primer lugar, el desarrollado anteriormente, que expone el nacimiento del deseo en contacto de la fluidez del agua y la naturaleza; luego vendría el momento en que la protagonista encauza el exceso de su deseo en la figura de su amante; para después, al final, desmontar su propio aparato de deseo, donde su voz es impugnada y subordinada al deseo esclerosado en el matrimonio.

Como bien quedó expuesto, el estanque es el lugar del devenir en conexión con la naturaleza que deconstruye la sexualidad binaria, abriéndose el campo de la subjetivación a la sensación intensa de apertura. No obstante, luego de ese episodio el deseo aparentemente se regulariza en un cuadro de sujeción binaria, donde el amante es la figura donde se decanta la pasión de la protagonista. Por lo anterior, para Oyarzún y Garrels, el deseo nunca escapa de la trama del sistema heterocentrado del género, donde el polo de lo masculino subordina a lo femenino, no obstante, para Susan Lucas Dobrian (1999) el amante se recubre de una textura especular, que bien no dice más que el deseo de constitución de identidad: «Por ser masculino, el desconocido agrega un tinte erótico en la textualización de identidad de la protagonista. Le afirma su deseo, y en términos lacanianos, le sirve de superficie especular donde la protagonista proyecta su deseo y lo ve reflejado» (155). Por lo tanto, la imagen especular de lo que ella desea de sí es refractada en el cuerpo del otro, que es un hombre ciego, muerto y silente. Ese hombre es un mero soporte de la inquietud deseante de la protagonista, no es un soporte sexuado desde donde se puedan regenerar las leyes de la sintaxis del poder.

Sin embargo, al generar este esquema binario ficcional del deseo, la protagonista accede a una realidad constituida de forma dual, y en contacto del significante. Ella, luego de los encuentros con su amante, rememora a través de la escritura sus episodios de pasión. De este modo, abre un espacio de autonomía que convierte a la escritura en una nueva técnica de subjetivación: "Al lograr establecer textos propios, la mujer deviene al mismo tiempo el sujeto y el objeto de su propio discurso, la creadora y la creación del proceso textual» (Lucas, 167). En ese sentido, la escritura femenina es la textualización de su propio deseo, siendo el proceso de su redacción la enunciación cifrada de cómo se tuerce la escritura del sujeto hegemónico. Así, Bombal ciñe su proceso creativo a la tradición de la escritura femenina como espacio de reflexión y autonomía?

Así, esta narrativa busca elidir el polo de la sujeción, construyendo una subjetivación que bien migra, o se vuelve hacia sus propios pliegues para contener la fuerza que la impacta: "Como una construcción imaginaria que fractura el canon social [...] por medio del deseo, desterritorializando así la disyunción masculino/femenino» (Espinosa, 18).

\footnotetext{
Lucía Guerra Cunningham (1991) establece que las mujeres pactaron en la escritura del yo un espacio negociado de autonomía. A su vez Rubí Carreño (20002) describe las estrategias en que María Luisa Bombal es insertada en el canon literario como la mujer princesa, la mujer otra orilla y la mujer travestida de la escritura masculina. Por último, otro antecedente de la escritura femenina, se encuentra en la Genealogía de la vanguardia de Subercaseux (1999), donde se expone que la corriente espiritualista usó la escritura como un espacio de reflexión, intimidad y autonomía.
} 
En general, esta interpretación se orienta a demostrar cómo se logra realizar una torcedura de las técnicas que construyen el sujeto, para dejar entrever la superficie deseante de los cuerpos a la cual la visibilidad del poder se aplica. En ese caso, La última niebla, demuestra tres formas de afrontar las diatribas con el poder, las dos primeras se basan en el deseo, una con la naturaleza y la otra con su amante. Ambas generan un desmontaje de la epistemología binaria de la construcción del sujeto, y en ambos casos se logra una deconstrucción de los términos en que el poder establece la sujeción por medio de la imposición de la ley. Sin embargo, en Bombal también está el triunfo de la voluntad del poder, lo cual marcaría un tercer momento donde el deseo es sometido.

Al final de La última niebla, la protagonista de la novela ha perdido la oportunidad de establecer su deseo en torno a su amante y la escritura. Su esposo, Daniel, se ha constituido como el garante de la ley del Padre y el significante, para generar la estructura del sujeto en el deseo de la protagonista. Ella busca a su amante, pero no lo encuentra, de ese modo se entera que la administración de la vida y su sujeción al matrimonio se le plantean como destino forzado: «Lo sigo para llevar a cabo una infinidad de pequeños menesteres, lo sigo para vivir correctamente, para morir correctamente» (Bombal, 85). Sin embargo, como antes ya se ha expuesto, la naturaleza biopolítica se descubre en su empresa de dominación cuando la protagonista impugna la tarea del poder en el mantenimiento de la vida: «Un destino implacable me ha robado hasta el derecho de buscar la muerte» (Bombal, 84). De este modo, luego del pretendido suicidio de Regina, las reflexiones en la novela comprenden el mantenimiento de la vida como una forma de muerte. Por lo que el triunfo del sujeto significa el develamiento de sus mecanismos y el desmontaje de las técnicas de administración de la vida, por lo cual la muerte es un horizonte válido como construcción de una experiencia al límite del filo del poder.

La trama del deseo en Bombal evade al sujeto, no sólo por construir una propia subjetivación, sino que por romper los marcos de la estabilidad que marginan la experiencia de la muerte: «Pulsión de muerte» significa precisamente que la tendencia de un organismo viviente es mantenerse en un estado de tensión, evitando la relajación final que conduce a un estado de homeostasis» (Žižek, Deleuze, 174). Por ende, el propósito de la escritura no se ciñe al proyecto de crear una superficie regular, sino que construye una tensión en las relaciones de deseo irreductibles a la cooptación del sujeto.

\section{DESEO, TENSIÓN Y SECRETOS}

Por último, para completar las figuras de tensión, ya no relacionadas necesariamente a la muerte, se puede argüir que la construcción de los objetos del deseo en Bombal tiende a una resistencia de su enunciación. En La última niebla el amante se construye como una alteridad donde se inscribe la pasión femenina, sin embargo, la superficie de esa alteridad es opaca. El amante es una figura especular, encerrado en su carruaje y ciego en su casa: «Ve el carruaje herméticamente cerrado, de donde se asoma su amante por una ventana, saluda y se va» (59). Por otra parte, en el cuento «Trenzas», uno de los episodios en que las mujeres se unen a sus trenzas, es cuando la esposa de un caballero de viaje va a la pieza cerrada, que su marido había indicado como espacio negado para su mujer. En ambos casos, lo deseado es un objeto hermético al cual se accede pero del cual no se deja cuenta a través de la enunciación. 
Un tercer caso, y el más interesante frente a este encubrimiento del objeto del deseo, es la relación con la escritura establecida por la protagonista de La última niebla. Como ya se ha señalado, la escritura en este caso era la utilización del significante para indicar el doblez de su autoridad, puesto que la escritura de las escenas de pasión no sigue la sintaxis del sometimiento del deseo femenino, sino que construyen su liberación. Pero no en un sentido epifánico, como si bajo el sujeto existiera una energía opaca y reluciente que emerge de las tinieblas como un sujeto más allá del sujeto sino como una opacidad de la línea de la fuerza que se vuelve contra sí misma. En ese sentido, la protagonista cierra su proceso de escritura con la siguiente acción enmarcada en La última niebla: «Escribo y rompo» (54), desde donde se puede interpretar una resistencia a utilizar la escritura para fijar el objeto, haciéndolo irreconocible con la borradura de su inscripción.

Este acto-reflejo, que bien se puede leer como una incapacidad de la protagonista, es una opción, que bien como incapacidad o no, funda una estrategia paralela a una formulación visible de lo deseable. En primer lugar, la técnica de la escritura se torció, haciendo que la sintaxis significante fuera rota una y otra vez, para así dar paso a una sintaxis de los silencios: «El silencio como primera respuesta [es] un «modo de expresarse», de responder a la agresividad. Así [...] la protagonista de La última niebla —que guarda su nombre para sí- comienza a encerrarse, a vivir para ella» (Bianchi, Sitio web). Volviendo atrás, ese vivir para ella en la escritura silenciada de papeles rasgados oculta su enunciación del deseo y la superficie erógena donde ella conecta su energía deseante.

De este modo, el proceso de encubrimiento de su enunciación se completa por la ocultación de los dos lados del deseo. Ella escribe y rompe sin dejar ver cómo es la escena donde ella se realiza. Por otra parte, su amante no se muestra; es un ciego encerrado en un carruaje, que al momento de preguntar por la veracidad de su existencia se escabulle al espacio de la muerte. Ambas estrategias describen una resistencia a un sistema que basa su subordinación en la visibilidad. La enunciación de su deseo la hubiese inscrito en el territorio simbólico gobernado por las fuerzas patriarcales, que de ningún modo hubiesen comprendido su acto de desear. Y aunque hubiese logrado la enunciación de su deseo, más valía optar por el encubrimiento porque: «No hay mayor violencia que la sufrida por un sujeto que es forzado, contra su voluntad, a exponer en público el objeto en sí mismo» (Žižek, «El superyó por defecto», 126). En palabras de Slavoj Žižek, era muy peligroso develar cuál era el objeto que extraído del sujeto (el objeto a) se volvía hacia afuera para lograr la constitución de la identidad. En otras palabras, con el encubrimiento y la resistencia de la enunciación del objeto a, el sujeto se plantea siempre como un porvenir, debido a que en sí es un sujeto vacío, aunque para estos efectos no importa que así lo sea, puesto que la estructura del sujeto no es la búsqueda de Bombal, por lo cual la resistencia de decir su deseo también implica la refracción del poder para que éste no entre en la nueva red tejida por esta enunciación construida en la opacidad.

En resumidas cuentas, lo que busca Bombal no es un sujeto, sino que una forma de escritura silente, un silencio quebrado, roto y fragmentado, escondido en un carruaje o en el fondo de una pieza, para que el poder no haga dócil el cuerpo insurrecto vuelto obra de arte más allá de la administración de la vida. Así, el silencio es la opacidad refulgente donde late el devenir de la subjetivación: «Silenciarse significa, de cierta manera, crearse un espacio de libertad: calladas, estas mujeres no permiten que otros — pertenecientes al mundo rechazado - penetren en sus intimidades» (Bianchi, Sitio web). De este modo, existe un espacio fuera del poder, este espacio se ha construido en base a una armonía cuya clave es una incógnita. Ese espacio abismal, florecido de trenzas y raíces, es un objeto en penumbra que se asoma también en los bordes de la escritura, pero no se dice, porque: 
El secreto se eleva del contenido finito a la forma infinita del secreto. Ahí es donde el secreto alcanza lo imperceptible absoluto, en lugar de remitir a todo un juego de percepciones y de reacciones relativas. Se pasa de un contenido bien determinado, localizado o pasado, a la forma general a priori de un algo que ha pasado, no localizable (Deleuze, 89).

Por lo tanto, el deseo y su enunciación, incluso la misma política mezclada a la estética, utilizan la estrategia del secreto para su puesta en escena. Por ende, los silencios son solidarios de una denuncia que no se debe convertir en pedagogía y propaganda, sino en una estética y una poética de silencios y conexiones con la naturaleza.

\section{CONCLUSIÓN}

En primer lugar, este trabajo buscó cerrar la incógnita que existía entre el sujeto y la subjetividad en las novelas de Bombal, sin embargo, esa interrogante abrió un campo cruzado por distintos vectores. De un lado estaban las recepciones críticas que acotaban el trabajo de la narradora a sus relaciones con la fantasía, por otro las de su deslinde del criollismo, y por último sus relaciones con una enunciación de carácter feminista. Para afrontar esas aproximaciones críticas, fue menester medir los propios testimonios de Bombal respecto de su labor creativa, debido a que las exigencias críticas planteadas han de ser confrontadas con los propósitos de la autora. A pesar de que los textos no están subordinados a una voluntad, las intenciones de su elaboración pueden declarar sus filiaciones estéticas. De este modo, para confrontar la falta de intencionalidad política de esta narrativa se ha expresado la propia opinión de la autora respecto de su quehacer, el que para ella estaba relacionado con sujetos minoritarios.

Por otra parte, continuando esta labor de recolección de las filiaciones estéticas, se halló la relación de Bombal con el espiritualismo de vanguardia, el que entregaba los elementos irracionalistas y oscurantistas de su poética. De este modo, los espacios fantasmagóricos y mortuorios encontraban su lugar en la enunciación antes que las declaraciones eminentemente políticas. Estos antecedentes determinan la construcción de un espacio imaginario, que no está exento de las polémicas del sujeto y la subjetivación, que deben ser leídas en su justa medida y ubicación.

Así, esta narrativa puede enfrentar el dilema de la biopolítica, como técnica de sujeción, desde una perspectiva estética. La que es construida en los relatos como resistencia al poder explorando los espacios vetados por su visibilidad. Imágenes como la muerte y la naturaleza no sólo cumplen con hacer una alusión estética de un mundo inexplorado, sino que están ahí para declarar la opacidad a la que son relegadas. Desde otra perspectiva, la muerte relacionada con la violencia, especialmente en La última niebla, se convierte en un oficio de leer detenidamente cómo el control de la autoridad masculina recubre la textura del deseo. El poder se infiltra hasta el punto de ser inevitable, sin embargo, la incomodidad que genera le permite a la protagonista torcer sus efectos. El develamiento del mecanismo de su funcionamiento y el acceso a la disrupción de la ley significante, por medio del uso de la escritura, hace que las nociones patriarcales se vuelvan hacia su opacidad. De esta forma, la enunciación está sometida a un tratamiento complejo que mezcla los referentes de la época y las propias convicciones para ser escenificadas en los relatos. 
Por último, las relaciones con la opacidad están estratégicamente dispuestas, puesto que exponer de forma directa el propósito de la escritura crearía un desmontaje de toda la trama argumental de las novelas. De este modo, el silencio y la ambigüedad hacen más tensa y productiva la relación establecida entre política y estética. Las novelas de Bombal se relacionan a una búsqueda de un espacio más allá del sujeto y su binarización entre identidad y alteridad. De modo que la construcción de los personajes apela a formar un ‘modo de existencia', donde la vida es una incógnita que se soluciona como una obra de arte, la cual cuestiona los materiales y técnicas que le dan factura.

\section{REFERENCIAS}

Bianchi, Soledad. «María Luisa Bombal o una difícil travesía (del amor mediocre al amor pasión)». Santiago: Cyber Humanitatis, 1997. Sitio web.

Bombal, María Luisa. «Testimonio autobiográfico». Obras completas. Barcelona: Andrés Bello, 1996. Medio impreso.

. La última niebla. Santiago: Nascimiento, 1941. Medio impreso.

. La amortajada. Santiago: Nascimiento, 1941. Medio impreso.

Carreño, Rubí. «Estereotipos e ideologías de género en Marta Brunet y Marías Luisa Bombal». Anales de literatura chilena (2002). 43-51. Medio impreso.

Deleuze, Gilles. Conversaciones: 1972-1990. Valencia: Pre-textos, 1999. Medio impreso. y Félix Guattari. Mil mesetas. Capitalismo y esquizofrenia. Barcelona: Pre-Textos, 1997. Medio impreso.

. Kafka por una literatura menor. México: Ediciones Era, 1983.

Espinosa, Patricia. «La última Niebla de María Luisa Bombal: excentricidad, desacato y eroticidad en el devenir identitario femenino». Acta Literaria 31 (2005). 9-21. Medio impreso.

Garrels, Elizabeth. "Ver y ser vista: La mirada fálica en La última niebla». Escritura: Revista de Teoría y Crítica Literarias 16, 31/32 (1991). 81-90. Medio impreso.

Guerra-Cunningham, Lucía. "Estrategias Narrativas de la mujer latinoamericana». Escritura: Revista de Teoría y Crítica Literarias 16, $31 / 32$ (1991). Medio impreso.

Lucas Dobrian, Susan. «La textualización del deseo: El amante desconocido en tres novelas femeninas». Revista Chilena de Literatura 55 (1999). 155-68. Medio impreso.

Méndez Rodenas, Adriana. El lenguaje de los sueños en La última Niebla: la metáfora de Eros». Revista iberoamericana 60, 168/169 (1994). 935-943. Medio impreso.

Oyarzún, Kemy. «El objeto del deseo. Historia e histeria en La última niebla». Poética del desengaño. Deseo, poder, escritura: Barrios, Bombal, Asturias y Yáñez. Santiago: Ediciones Lar, 1989. 89-119. Medio impreso.

Subercaseux, Bernardo. Genealogía de la vanguardia. Santiago: Universidad de Chile, 1999. Medio impreso.

Žižek, Slavoj. "Deleuze». Ensayos sobre biopolítica. Excesos de vida. Gabriel Giorgi y Fermín Rodríguez (comp.). Buenos Aires: Paidós, 2007. 141-186. Medio impreso. . «El superyó por defecto». La metástasis del goce: Seis ensayos sobre la mujer y la causalidad. Buenos Aires: Paidós, 2003. 88-132. Medio impreso. 